\title{
The Contribution Chemical Microscopy to the Solution of the Green River Murders
}

Skip Palenik

Microtrace LLC, 790 Fletcher Drive, Suite 106, Elgin, IL 60123

Microscopic trace evidence is sometimes assumed by lay people, and some forensic scientists as well, to have outlived its usefulness and to have been supplanted by DNA. The truth is, the search for, detection, isolation, identification and interpretation of microscopic traces is one of the most important tools available to the investigator in the solution of baffling crimes. It is unlikely, for example, that either the first World Trade Center bombing or the Oklahoma City bombing would have been solved as quickly and efficiently as they were without the significant contributions made by trace evidence that was collected and analyzed by the FBI laboratory. DNA played no significant role in these investigations. Its value was in the help it provided in identification of the victims.

The search for and examination of trace evidence played a critical role in the final solution of the Green River Murders - the biggest serial murder case in U.S. history. It also provided an interesting opportunity for the forensic scientists involved in the investigation to have their theories confirmed by the one person who knew the whole truth of the case - the killer himself.

In July of 1982, the dead bodies of four young women, who had earlier been reported missing, were found in and on the banks of the Green River, which runs through Seattle. By the early 1990s, the Green River Killer, as the unknown suspect came to be called, was credited with the murders of between 60 and 104 young prostitutes who worked in and around the SeaTac strip near the airport. Shortly after the murders began, a task force was formed to investigate the killings, but although thousands of leads were investigated, by the end of the nineties, the murders appeared to have stopped without a suspect ever having been charged.

In the fall of 2001, as a result of advances in DNA technology, a suspect named Gary Ridgway was charged with four of the Green River murders. Ridgway had been regarded as a suspect during the investigation, but had been questioned and released after he passed two lie detector tests and didn't match the profile that had been developed for the killer. Ridgway stated that although he didn't dispute being a customer of the four dead prostitutes, he was only a customer of theirs and did not murder them. The task force was concerned that they only had enough evidence to charge Ridgway in four of what they believed to be a string of as many as 100 murders.

In July of 2002 the author was contacted by Jeff Baird of the Green River Task Force and asked to assist in the examination of the trace evidence in the case. Specifically, we were asked to concentrate on and conduct examinations of microscopic paint particles that had been collected during the course of the investigation over the years and compare them to paint from Ridgway's work locker, home and automobile that were recovered when he was brought in for questioning in 1987. We began our work, but after conducting several thousand individual paint 
comparisons, no associations could be made between the known paint samples collected from Ridgway's environment and the paint particles associated with many of the victims.

During the course of our dust investigations, however, we noticed that spherical particles of spray paint were present in the dust we vacuumed from some of the victim's clothing. These particles were two orders of magnitude smaller than the smallest particles of paint that had been isolated up to this point. Jeff Baird gave permission to conduct these new examinations, and clothing (that still existed - many of the bodies were skeletons when discovered and had no clothing with them) of the uncharged victims was promptly delivered to us. The dust from the clothing was collected and we then began the painstaking task of picking through the dust samples under a stereomicroscope to search for and collect particles of spray paint.

To everyone's surprise, the dust from the victims' contained significant numbers of colored paint spheres. To those of us who analyze dust for a living, the finding of a spray paint particle or two or the same color (usually a shade of white) is not an unusual occurrence. In this instance, we would expect more than a few particles (of the same color). We were not prepared for the (in some cases) dozens of spray paint spheres of different colored paint found in the dust from the victims' clothing. The presence of large numbers of a certain particle type indicates proximity, in place or time, to a source. Since these women were prostitutes, and not graffiti artists, the finding of spray paint spheres, in different colors and large numbers was suspicious.

The microscopical and microchemical techniques we applied to eventually connect six of the victims to Ridgway will be presented. This included, strengthening the evidence from two of the victims who had been associated with Ridgway by DNA as well as four more victims who were charged to him strictly on the basis of the microscopic trace evidence we developed. Based on our evidence Ridgway, confessed to the murders of 48 women and believes he killed as many as 70. In 2004 he was sentenced to many life sentences, insuring that he will never hunt victims again.

This presentation will show images of the microscopic evidence never before shown to the public and will be augmented with video footage from two of the documentaries that have been produced about this case that illustrate the background as well as the role of microscopy and its direct outcome to the final solution. 